\title{
Application of Green Solvents for Rare Earth Element Recovery from Aluminate Phosphors
}

\author{
Clive H. Yen * $*$ and Rui Cheong
}

Department of Cosmetic Science, Providence University, Taichung City 43301, Taiwan; g1090361@gm.pu.edu.tw * Correspondence: kamehameha@pu.edu.tw; Tel.: +886-4-2632-8001 (ext. 15416)

check for updates

Citation: Yen, C.H.; Cheong, R. Application of Green Solvents for Rare Earth Element Recovery from Aluminate Phosphors. Minerals 2021, 11, 287. https://doi.org/10.3390/ $\min 11030287$

Academic Editor: Zenixole Tshentu and Durga Parajuli

Received: 28 January 2021

Accepted: 9 March 2021

Published: 10 March 2021

Publisher's Note: MDPI stays neutral with regard to jurisdictional claims in published maps and institutional affiliations.

Copyright: (c) 2021 by the authors. Licensee MDPI, Basel, Switzerland. This article is an open access article distributed under the terms and conditions of the Creative Commons Attribution (CC BY) license (https:/ / creativecommons.org/licenses/by/ $4.0 /)$.

\begin{abstract}
Two processes applying green solvents for recovering rare earth elements (REEs) from different types of aluminate phosphors are demonstrated in this report. For magnesium aluminatetype phosphors, a pretreatment with peroxide calcination was implemented first, and then followed by a supercritical fluid extraction (SFE) process. Supercritical carbon dioxide $\left(\mathrm{sc}-\mathrm{CO}_{2}\right)$ provides an effective and green medium for extracting REEs from dry materials. With the addition of a complex agent, tri-n-butyl phosphate-nitric acid complex, highly efficient and selective extraction of REEs using supercritical carbon dioxide can be achieved. The highest extraction efficiency was $92 \%$ for europium from the europium doped barium magnesium aluminate phosphor (BAM), whereas the highest extraction selectivity was more than $99 \%$ for the REEs combined from the trichromatic phosphor. On the other hand, for strontium aluminate type phosphors, a direct acid leaching process is suggested. It was found out that acetic acid, which is considerably green, could have high recovery rate for dysprosium ( $>99 \%)$ and europium ( $~ 83 \%)$ from this strontium aluminate phosphor materials. Nevertheless, both green processes showed promising results and could have high potential for industrial applications.
\end{abstract}

Keywords: rare earth elements; phosphors; supercritical carbon dioxide; aluminate; acid leaching

\section{Introduction}

Rare earth elements (REEs) have grown much in interest and demand in recent years due to their unique properties, which are irreplaceable in making modern electronic devices [1-3]. However, mining new minerals for REEs may be very costly both economically and environmentally [4]. Recycling REEs from waste materials can provide a sustainable way of reducing our needs for mining rare earth minerals [5,6]. One of the materials which contains a decent amount of REEs is the phosphor materials used in fluorescent lamps. Since fluorescent lamps are used in everyday life and in most households, spent fluorescent lamps are estimated to be buried every year in huge numbers, more than 600 million in the USA alone, which roughly contain 1350 tons of REEs by our calculations [7]. As for the case in Taiwan, about 5 million kilograms of scrap fluorescent lamps have been recycled per year, which contained about 29 tons of phosphor powder [8]. The phosphor materials in the spent lamps can be recycled for reuse as some recycling facilities have developed technologies aimed specifically for such applications [9]. Another approach is to recover the REEs present from the phosphor materials collected from the spent lamps [10-14]. This approach cannot be done on an industrial scale yet since it requires economically viable extraction technologies to achieve.

There are many different types of phosphor materials used in the fluorescent lamps and aluminate-type phosphors are popularly used in the long-life lamps. It is well known that the aluminate-type phosphors, especially magnesium aluminates, are very stable since their structures are related to aluminum oxide. They are insoluble in acid solutions and therefore, it is very difficult to extract the REEs doped in the aluminate structures. In the literature, some reports have suggested that using a strong base or oxidizing agent 
can help convert REEs into their oxide forms, which are soluble in strong acid solutions. Wu et al. investigated the calcination of sodium peroxide with the green phosphor $\left(\mathrm{Ce}_{0.67} \mathrm{~Tb}_{0.33} \mathrm{MgAl}_{11} \mathrm{O}_{19}\right)$ [15]. They found that optimal conditions for this peroxide treatment are temperatures of $650{ }^{\circ} \mathrm{C}$ for a time of $50 \mathrm{~min}$, and a peroxide to phosphor mass ratio of 1.5:1. After applying the peroxide treatment to the phosphors, the REEs can be easily transformed into their oxide forms by a second calcination in air or in oxygen gas. Liu et al. used sodium hydroxide for alkali sintering of the phosphor materials [16]. They reported that with the sintering step, the leaching rates of the REEs all improved by more than $70 \%$. Moreover, both blue $\left(\mathrm{Ba}_{0.9} \mathrm{Eu}_{0.1} \mathrm{MgAl}_{10} \mathrm{O}_{17}\right)$ and green $\left(\mathrm{Ce}_{0.67} \mathrm{~Tb}_{0.33} \mathrm{MgAl}_{11} \mathrm{O}_{19}\right)$ phosphors could apply the same sintering conditions, i.e., $800^{\circ} \mathrm{C}$ for $2 \mathrm{~h}$, which would be very convenient, since the different phosphors are pre-mixed in many situations. Zhang et al. studied the effects of acid leaching and alkali fusion from waste fluorescent powders [17]. They found out that hydrochloric acid performed better than sulfuric acid in the first acid leaching step. Moreover, using sodium hydroxide is better than sodium carbonate in the alkali fusion process at $800{ }^{\circ} \mathrm{C}$ for $2 \mathrm{~h}$. The leaching rates for the REEs all exceeded $97 \%$.

In order to achieve selective extraction or separation of the REEs, multi-solvent systems have been used. Yang et al. used different acids and ionic liquids to separate the REEs from the phosphor materials [18]. In the first stage, the phosphors were leached with sulfuric acid. Combined with filtration and ionic liquid extraction, a high purity of yttrium and europium could be obtained. When moving on to the second stage, the residue phosphors were leached by nitric acid instead, and after more filtration and ionic liquid extraction, the other REEs could be obtained also in high purity. Other than utilizing traditional solvent extraction, supercritical fluid extraction (SFE) can provide an alternative way for recovering REEs from electronic wastes [19]. SFE can reduce the production of liquid waste since liquid solvents are substituted by supercritical carbon dioxide $\left(\mathrm{sc}-\mathrm{CO}_{2}\right)$, which can be recycled and reused or released as a gas. To the best of our knowledge, there is only one report that used sc- $\mathrm{CO}_{2}$ for extracting REEs from phosphor materials. Shimizu et al. demonstrated a SFE process by using a tri-n-butylphosphate-nitric acid $\left(\mathrm{TBP}-\mathrm{HNO}_{3}\right)$ complex ligand for extracting REEs from phosphor materials [20]. They reported that the REEs in the red phosphor, which is yttrium oxide doped with europium, could be effectively recovered. However, the REEs in non-oxide phosphors, such as lanthanide phosphates, showed very low extraction efficiencies.

In this research, we report an SFE process for extracting REEs from the simulated and real waste phosphors that were used in fluorescent lamps. The waste phosphors were pre-treated with a sodium peroxide calcination process prior to SFE. High extraction efficiencies of the REEs ( $\mathrm{Y}, \mathrm{Eu}$ and $\mathrm{Tb}$ ) from the treated phosphors could be achieved by the SFE process. An interesting observation is that when using a TBP- $\mathrm{HNO}_{3}$ complex as the chelating agent in our SFE process, the REEs could be extracted selectively, i.e., the REEs and the non-rare earth metals could be separated. This simple batch extraction process using sc- $\mathrm{CO}_{2}$ could achieve similar results as the ones reported in the literature using multisolvent systems. The SFE process described in this paper may provide an environmentally sustainable and economically viable method for recycling REEs from fluorescent lamps and other electronic wastes. In addition, a strontium aluminate phosphor doped with Dy and $\mathrm{Eu}$, which is a relatively new cosmetic material for glowing, was also investigated for the first time in recycling the REEs. Surprisingly, this type of phosphor did not require any pretreatment and could undergo acid leaching directly. Therefore, this report also included an alternative green process by organic acid leaching for the strontium aluminate phosphor and the results were comparable to conventional mineral acid leaching methods.

\section{Materials and Methods}

\subsection{Chemicals and Materials}

All phosphors were purchased from Sigma-Aldrich including europium doped yttrium oxide $\left(\mathrm{Y}_{1.92} \mathrm{Eu}_{0.08} \mathrm{O}_{3} ; \mathrm{YOE}\right.$; red phosphor), terbium doped cerium magnesium aluminate $\left(\mathrm{Ce}_{0.63} \mathrm{~Tb}_{0.37} \mathrm{MgAl}_{11} \mathrm{O}_{19}\right.$; $\mathrm{CAT}$; green phosphor), europium doped barium magnesium 
aluminate $\left(\mathrm{Ba}_{0.86} \mathrm{Eu}_{0.14} \mathrm{MgAl}_{10} \mathrm{O}_{17} ; \mathrm{BAM}\right.$; blue phosphor), and trichromatic phosphor (TRI; simulated waste), which is a mixture of the three aforementioned phosphors by one-third of each. Moreover, a long persistent green phosphor, europium and dysprosium doped strontium aluminate $\left(\mathrm{Sr}_{0.95} \mathrm{Eu}_{0.02} \mathrm{Dy}_{0.03} \mathrm{Al}_{2} \mathrm{O}_{4} ; \mathrm{SRA}\right)$ was purchased from Sigma-Aldrich. Tri-n-butylphosphate $\left(\left[\mathrm{CH}_{3}\left(\mathrm{CH}_{2}\right)_{3} \mathrm{O}\right]_{3} \mathrm{PO} ; \mathrm{TBP} ; 97 \%\right)$ was purchased from Sigma-Aldrich; hydrochloric acid ( $\mathrm{HCl}$; concentrated; ACS grade) was purchased from EMD Millipore; nitric acid $\left(\mathrm{HNO}_{3}\right.$; concentrated; $\mathrm{ACS}$ grade) was purchased from Macron Fine Chemicals; carbon dioxide tank was purchased from Matheson Tri-Gas; sodium peroxide $\left(\mathrm{Na}_{2} \mathrm{O}_{2}\right.$; $95 \%$ ) was purchased from Alfa Aesar; hydrogen peroxide $\left(\mathrm{H}_{2} \mathrm{O}_{2} ; 30 \%\right.$; ACS grade) was purchased from EMD Millipore; citric acid $\left(\mathrm{C}_{6} \mathrm{H}_{8} \mathrm{O}_{7} ; 99.8 \%\right.$; ACS grade) and acetic acid $\left(\mathrm{CH}_{3} \mathrm{COOH} ; 99.7 \%\right.$; ACS grade) were purchased from J.T.Baker (Phillipsburg, NJ, USA). All chemicals were used as received.

\subsection{Experimental Apparatus}

Inductively coupled plasma-optical emission spectroscopy (ICP-AES) analysis was performed on iCAP 6300 DV (Thermo Scientific, Austin, TX, USA) and inductively coupled plasma-mass spectroscopy (ICP-MS) analysis was performed on Agilent 7700 (Agilent Technologies, Santa Clara, CA, USA). The sc- $\mathrm{CO}_{2}$ syringe pump is from ISCO $260 \mathrm{D}$ (Teledyne ISCO, Lincoln, NE, USA) and the extraction system is shown on Figure 1. The extraction cell is placed on top of a hot plate with stirring and is connected to the output of the syringe pump with a pressure indicator. The output of the reaction cell is connected to a needle valve, which can control the flow rate, and is then passed through a trap solution.

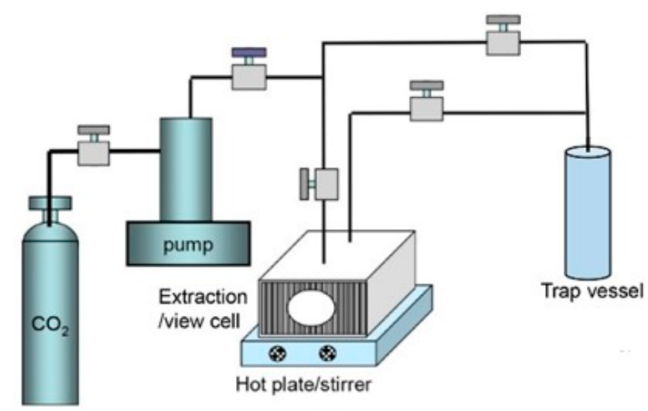

Figure 1. Schematic diagram of the SFE system.

\subsection{Aluminate Phosphors Pretreatment Procedures}

The pretreatment conditions for the phosphor materials were from a previous report by Wu et al. [15] In a typical trial, aluminate phosphor powder of $300 \mathrm{mg}$ and sodium peroxide of $450 \mathrm{mg}$ were put inside a ceramic or nickel crucible. The crucible was then put inside a furnace with a temperature of $650{ }^{\circ} \mathrm{C}$ for $1 \mathrm{~h}$ calcination. After calcination, the powder was collected for further experiments.

\subsection{Acid Digestion Procedures}

For complete digestion of the calcined phosphors, $10 \mathrm{~mL}$ of concentrated $\mathrm{HCl}$ and $10 \mathrm{~mL}$ of $30 \% \mathrm{H}_{2} \mathrm{O}_{2}$ were added to $100 \mathrm{mg}$ of the calcined phosphor powder inside a round bottom flask with an oil bath. The reaction temperature was $60^{\circ} \mathrm{C}$ and reaction time was $2 \mathrm{~h}$ with stirring of $350 \mathrm{rpm}$. After the reaction, $1 \mathrm{~mL}$ of the solution was taken out and diluted for ICP-AES and ICP-MS analysis.

For the organic acid leaching, in a typical trial, $50 \mathrm{~mL}$ of $10 \%$ acetic acid was added to $100 \mathrm{mg}$ of the SRA powder inside a round bottom flask with water bath of $50{ }^{\circ} \mathrm{C}$. For sampling, an aliquot of $0.5 \mathrm{~mL}$ was taken out each time and diluted for ICP analysis.

\subsection{Complex Preparation and Leaching Procedures}

The preparation of the tributyl phosphate-nitric acid (TBP- $\left.\mathrm{HNO}_{3}\right)$ complex was from a previous report by Shimizu et al. [20] In a typical trial, the complex was prepared by 
adding $2 \mathrm{~mL}$ of TBP and $2 \mathrm{~mL}$ of concentrated $\mathrm{HNO}_{3}$ together inside a glass vial. After shaking the vial for $30 \mathrm{~min}$, centrifugation was applied for $5 \mathrm{~min}$ with $4000 \mathrm{rpm} ; 2 \mathrm{~mL}$ of the upper phase was pipetted into another glass vial and diluted with $0.5 \mathrm{~mL}$ of TBP. This TBP- $\mathrm{HNO}_{3}$ complex has a composition of TBP: $\mathrm{HNO}_{3}: \mathrm{H}_{2} \mathrm{O}=1: 1.3: 0.4$.

For complex leaching, $2.5 \mathrm{~mL}$ of the prepared TBP- $\mathrm{HNO}_{3}$ complex was added to $10 \mathrm{mg}$ of the treated phosphor powder in a glass vial with an oil bath. The reaction temperature was $60{ }^{\circ} \mathrm{C}$ and the reaction time was $24 \mathrm{~h}$ with stirring of $350 \mathrm{rpm}$. After the reaction, $1 \mathrm{~mL}$ of the complex was taken out and back-extracted with $20 \mathrm{~mL}$ of $5 \% \mathrm{HNO}_{3}$ for ICP analysis.

\subsection{Supercritical $\mathrm{CO}_{2}$ Extraction Procedures}

In a typical trial, $10 \mathrm{mg}$ of the treated phosphor powder was put inside the high pressure cell with $2.5 \mathrm{~mL}$ of the $\mathrm{TBP}-\mathrm{HNO}_{3}$ complex. The first step was the static extraction of $2 \mathrm{~h}$, the $\mathrm{CO}_{2}$ pressure was set to $20.7 \mathrm{MPa}$ (3000 psi) and temperature was set to $60^{\circ} \mathrm{C}$. The second step was the dynamic extraction of $2 \mathrm{~h}$ and the $\mathrm{CO}_{2}$ flow rate was controlled to be at least $0.3 \mathrm{~mL} / \mathrm{min}$. After the dynamic extraction, the system was allowed to slowly depressurize into an atmospheric pressure for up to $6 \mathrm{~h}$. The trap solution, which is $5 \mathrm{M}$ of $\mathrm{HNO}_{3}$, was analyzed by ICP.

\subsection{Efficiency and Selectivity Definition}

The leaching or extraction efficiency is the ratio of the metal mass collected in the leachate or the trap solution to the metal mass inside the phosphor materials: Leaching or extraction efficiency $(\mathrm{EFF} \%)=($ collected metal mass $/$ loaded metal mass $) \times 100 \%$

The selectivity of rare earth is the ratio of the rare earth metal mass to the total metal mass collected in the leachate or the trap solution: Selectivity of rare earth $(\mathrm{RE} \%)=($ collected rare earth mass/collected total metal mass) $\times 100 \%$

\section{Results and Discussion}

\subsection{Pretreatment and Acid Digestion of the Phosphors}

The commercially available YOE, CAT, and BAM phosphors have chemical formulas of $\mathrm{Y}_{1.92} \mathrm{Eu}_{0.08} \mathrm{O}_{3}, \mathrm{Ce}_{0.63} \mathrm{~Tb}_{0.37} \mathrm{MgAl}_{11} \mathrm{O}_{19}$, and $\mathrm{Ba}_{0.86} \mathrm{Eu}_{0.14} \mathrm{MgAl}_{10} \mathrm{O}_{17}$, respectively. The trichromatic phosphor (TRI) is a mixture of the three aforementioned phosphors and was applied as a simulated waste. Yttrium has the highest composition in the phosphor materials, while europium, cerium and terbium have lower contents. It is important to recycle $\mathrm{Eu}, \mathrm{Tb}$ and $\mathrm{Y}$ since they are classified as critical REEs by the US Department of Energy. The phosphor powders, with the exception of YOE, were all calcined with $\mathrm{Na}_{2} \mathrm{O}_{2}$ in air at $650{ }^{\circ} \mathrm{C}$ for $1 \mathrm{~h}$ with a mass ratio of $\mathrm{Na}_{2} \mathrm{O}_{2}$ :phosphor $=1.5: 1$ [15]. After calcination, the aluminate phosphors transformed to their different metal oxides. The detailed reactions and structure changes of the phosphors can be referred to these reports [21,22]. Moreover, color changes were observed for the phosphors as BAM changed from white to grey, CAT changed from white to orange red and the TRI changed from white to reddish grey (Figure 2).

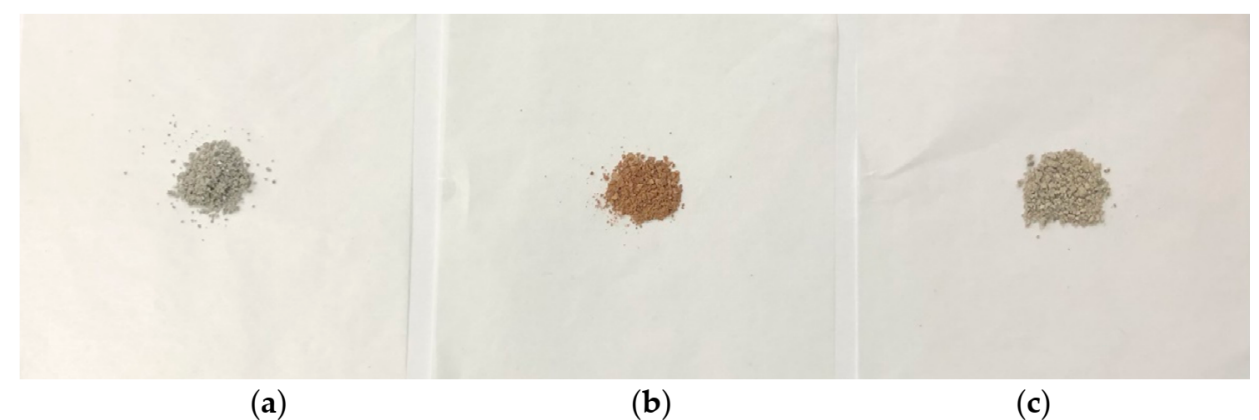

Figure 2. Phosphor powders after calcination. $(\mathbf{a})=$ BAM phosphors; $(\mathbf{b})=$ CAT phosphors; $(\mathbf{c})=$ TRI phosphors. (The size of the weighing paper is $9 \mathrm{~cm} \times 9 \mathrm{~cm}$ ) 
The metal content of the calcined phosphors can be acquired by digesting the phosphors in hydrochloric acid with the aid of hydrogen peroxide and the results are shown in Table 1. It is noticeable that without the calcination procedure the phosphors would not be completely digested. It is also noticeable that the combined metal mass only contained about half of the phosphor material mass. The remaining mass is mainly oxygen, which is included in the formation of oxides and possibly of water since the powders are slightly hygroscopic.

Table 1. Metal content (wt.\%) of different phosphors.

\begin{tabular}{cccccccccccc}
\hline Phosphor & Ce & Dy & Eu & La & Tb & Y & Al & Ba & Mg & Na & Sr \\
\hline BAM & - & - & 1.1 & - & - & - & 26.6 & 6.7 & 2.7 & 16.9 & - \\
CAT & 4.2 & - & - & - & 2.9 & - & 18.8 & - & 1.5 & 14.2 & - \\
TRI & 2.4 & - & 1.9 & - & 1.7 & 23.1 & 20.3 & 0.9 & 1.6 & 17.4 & - \\
Real waste & 2.1 & - & 1.3 & 5.0 & 1.5 & 20.0 & 8.5 & 1.5 & 1.1 & 12.1 & 8.6 \\
SRA ** & - & 1.5 & 0.7 & - & - & - & 25.4 & - & - & - & 45.1 \\
\hline
\end{tabular}

${ }^{*}$ Minor impurities not included here. ${ }^{* *}$ SRA not calcined. -: not detected.

\section{2. $\mathrm{TBP}-\mathrm{HNO}_{3}$ Complex Preparation and Leaching}

In order to apply sc- $\mathrm{CO}_{2}$ extraction, a commonly used extracting adduct for uranium and for lanthanides, i.e., tributyl phosphate-nitric acid (TBP- $\left.\mathrm{HNO}_{3}\right)$, was chosen for the experiments. TBP has a high solubility in sc- $\mathrm{CO}_{2}$ and is known for extracting REEs from water, especially in acid solutions [23]. In SFE systems, TBP is often mixed with nitric acid as they can form a $\mathrm{CO}_{2}$-soluble complex for extracting lanthanides and actinides. Typically, the $\mathrm{TBP}-\mathrm{HNO}_{3}$ complex is prepared by mixing the TBP with concentrated nitric acid with a 1:1 volume ratio. After vigorous mixing, the upper phase (TBP phase) is taken as the complex for SFE. However, this typical complex is not suitable for a batch extraction system since the water content is relatively high, which can interfere with the sc- $-\mathrm{CO}_{2}$ extraction [20,24]. Accordingly, a 20\% dilution of the complex with extra TBP can make it more suitable for sc- $\mathrm{CO}_{2}$ extraction in a batch system. Therefore, the $\mathrm{TBP}-\mathrm{HNO}_{3}$ complex was first tested to evaluate its leaching ability before applying it into the sc- $\mathrm{CO}_{2}$ system. Table 2 shows that the TBP- $\mathrm{HNO}_{3}$ complex has high leaching efficiency for the REEs and magnesium and low leaching efficiency for sodium, aluminum and barium. This is related to the different solubility of the metal oxides in the TBP- $\mathrm{HNO}_{3}$ complex phase. Therefore, a separation of the REEs and the non-rare earth metals would occur simultaneously. However, since the leaching efficiency of $\mathrm{Mg}$ was more similar to the REEs, the RE\% were only $17 \%$ and $59 \%$ for BAM and CAT, respectively. In the case of TRI, since the $\mathrm{Mg}$ content was less than $7 \%$ of $\mathrm{Y}$, the $\mathrm{RE} \%$ maintained a high value of $86 \%$. Moreover, according to several previous reports, calcination of the phosphors with $\mathrm{Na}_{2} \mathrm{O}_{2}$ or $\mathrm{NaOH}$ would result in a water-soluble product, $\mathrm{NaAlO}_{2}[16,25]$. The $\mathrm{NaAlO}_{2}$ would be washed away by water during the powder collecting procedure. Therefore, the low $\mathrm{Al}$ content would have less interference for recovering and purifying REEs in later stages.

Table 2. Complex leaching efficiency (EFF\%) of each metal from the calcined phosphors.

\begin{tabular}{cccccccccc}
\hline Phosphor & Ce & Eu & Tb & Y & Al & Ba & Mg & Na & RE\% * \\
\hline BAM & - & 90.9 & - & - & 9.4 & 0.1 & 66.7 & 3.0 & 16.8 \\
CAT & 92.9 & - & 93.1 & - & 16.0 & - & 73.3 & 3.5 & 59.1 \\
TRI & 70.8 & 73.7 & 70.6 & 69.3 & 9.8 & 0.1 & 56.3 & 2.9 & 86.0 \\
\hline * RE $\%$ (
\end{tabular}

\subsection{Supercritical $\mathrm{CO}_{2}$ Extraction of the Phosphors}

The SFE system is like an extension of the complex leaching system. Not only do the metals need to be leached out from the calcined phosphors but they also need to form $\mathrm{CO}_{2}$-soluble complexes with TBP and $\mathrm{HNO}_{3}$ in order to be transferred by sc- $\mathrm{CO}_{2}$ into the collecting trap solution. The sc- $\mathrm{CO}_{2}$ extraction results are shown in Table 3 . When 
comparing the results with complex leaching, the extraction efficiency maintained about the same for BAM and TRI, whilst a decrease occurred for CAT, especially for Ce extraction. A possible explanation for this is that normally the REEs form complexes with $\mathrm{TBP}-\mathrm{HNO}_{3}$ in their $3+$ oxidation state. However, during the calcination process, $\mathrm{Ce}$ and $\mathrm{Tb}$ could form oxides with mixtures of $3+$ and $4+$ oxidation states $[15,26]$. Normally, TBP- $\mathrm{HNO}_{3}$ and the 3 + oxides, $\mathrm{Ce}_{2} \mathrm{O}_{3}$ and $\mathrm{Tb}_{2} \mathrm{O}_{3}$, could form complexes, such as $\mathrm{Ce}\left(\mathrm{NO}_{3}\right)_{3}(\mathrm{TBP})_{3}$ and $\mathrm{Tb}\left(\mathrm{NO}_{3}\right)_{3}(\mathrm{TBP})_{3}$, which have good solubility in $\mathrm{CO}_{2}$. The $4+$ oxides, $\mathrm{CeO}_{2}$ and $\mathrm{Tb}_{4} \mathrm{O}_{7}$, however, need more TBP- $\mathrm{HNO}_{3}$ to form $\mathrm{CO}_{2}$-soluble complexes, possibly $\mathrm{Ce}\left(\mathrm{NO}_{3}\right)_{4}(\mathrm{TBP})_{2}$ and $\mathrm{Tb}\left(\mathrm{NO}_{3}\right)_{4}(\mathrm{TBP})_{2}$ [27]. From a report by Baek et al., cerium oxide $\left(\mathrm{CeO}_{2}\right)$ had very limited extraction efficiency under the sc- $\mathrm{CO}_{2}$ extraction system [28]. Furthermore, $\mathrm{Ce}_{2} \mathrm{O}_{3}$ is known to oxidize into $\mathrm{CeO}_{2}$ in open air and $\mathrm{CeO}_{2}$ can be difficult to dissolve in nitric acid, thus causing Ce to be more difficult to extract than $\mathrm{Tb}$ [29]. We believe that these are the main reasons that have caused lower Ce extraction.

Table 3. Supercritical fluid extraction efficiency (EFF\%) of each metal from the calcined phosphors.

\begin{tabular}{ccccccccccc}
\hline Phosphor & Ce & Eu & La & Tb & Y & Al & Ba & Mg & Na & RE\% * \\
\hline BAM & - & 92.0 & - & - & - & 0.1 & 0.1 & 0.7 & 0.3 & 86.6 \\
CAT & 44.8 & - & - & 84.0 & - & 0.1 & - & 0.3 & 0.1 & 98.8 \\
TRI & 73.4 & 70.2 & - & 80.2 & 70.2 & 0.2 & 0.1 & 0.7 & 0.1 & 99.7 \\
$\begin{array}{c}\text { Real } \\
\text { waste }\end{array}$ & 46.7 & 82.0 & 18.9 & 80.2 & 85.3 & 0.1 & 0.1 & 0.3 & 0.1 & 99.8 \\
\hline * & & & & & & & & & &
\end{tabular}

${ }^{{ }^{*} \mathrm{RE} \%}=$ (collected rare earth mass/collected total metal mass $) \times 100 \%$.

The $\mathrm{RE} \%$ during sc- $\mathrm{CO}_{2}$ extraction all increased from the complex leaching and had high values for at least $86 \%$ in BAM and up to $99 \%$ for the cases in CAT and TRI. These results show that the non-rare earth metals have limited extraction in the $\mathrm{sc}-\mathrm{CO}_{2}$ system. However, some non-rare earth metals, such as $\mathrm{Mg}$ and $\mathrm{Al}$, can be leached out by the TBP$\mathrm{HNO}_{3}$ complex. These non-rare earth metals either do not form $\mathrm{CO}_{2}$-soluble complexes or their complexes have a low solubility in $\mathrm{CO}_{2}$ within the experimental conditions. To summarize this process, the experimental results can be considered a significant improvement, since previous studies have shown that SFE could only extract the REEs from the red phosphor, which are $\mathrm{Y}$ and $\mathrm{Eu}$ [20]. However, Ce may have some limitation to be fully extracted in sc- $\mathrm{CO}_{2}$, the critical REEs ( $\mathrm{Y}, \mathrm{Eu}$ and $\mathrm{Tb}$ ) are very suitable for being extracted in sc- $\mathrm{CO}_{2}$. On the other hand, all the non-rare earth metals had almost no extraction. Therefore, these results successfully demonstrated the first example of sc- $\mathrm{CO}_{2}$ extraction of a mixture of different phosphor materials with a high extraction efficiency and selectivity.

\subsection{Supercritical $\mathrm{CO}_{2}$ Extraction of Real Waste Phosphors}

Real waste phosphor samples were also studied in this research. The waste samples were collected from spent compact fluorescent light bulbs (SYLVANIA TWIST). It should be noted that since mercury is present in every fluorescent light bulb, safety precautionary actions need to be taken during collecting of the phosphor samples [30]. In brief, the light bulbs were cut open from the glass-metal interface near the end of the bulb under a $30 \%$ acetone solution to prevent mercury vapor leaking. The spiral glass portion containing the phosphor powder was then ultrasonicated to detach the phosphor powder from the inner glass. After careful washing and drying of the powder, the real waste phosphor samples went through the same procedures as the simulated waste, which is the pretreatment of calcination with $\mathrm{Na}_{2} \mathrm{O}_{2}$. The metal content of the calcined waste phosphor is also listed in Table 1 and it was found out that the trace mercury was undetected in the remaining samples. In addition, lanthanum, which was not contained in the simulated waste, was present in the real waste sample. According to the literature, most commercial lighting products contain REE phosphors of YOE, BAM, CAT, CBT ((Ce,Gd) $\left.\mathrm{MgB}_{5} \mathrm{O}_{10}: \mathrm{Tb}\right)$, and $\mathrm{LAP}\left(\mathrm{LaPO}_{4}: \mathrm{Ce}, \mathrm{Tb}\right)$ [31]. Therefore, the LAP phosphor, which is a non-aluminate phosphor, should be the source of lanthanum. After pretreatment, the calcined sample underwent the SFE process and the extraction results are listed in Table 3. High extraction 
efficiency for the REEs were observed for $\mathrm{Eu}, \mathrm{Tb}$, and $\mathrm{Y}$, whereas lower extraction efficiency was observed for Ce and La. As mentioned before, the low EFF\% for Ce may be due to the influence of its oxidation state. However, in the case for La, the reason of the low $\mathrm{EFF} \%$ is still unclear and it is speculated that it may be related to its counter anion. The phosphate may be competing with nitrate to form complex with TBP, and therefore, lower the extraction kinetics. This phenomenon was also observed by a previous study and will need further investigation [20]. On the other hand, the selectivity RE\% was consistent with the simulated waste samples which remained at a high level ( $>99 \%)$. This proved that the SFE process favors the extraction of REEs over non-rare earth metals and could be very useful to practical applications.

\subsection{Direct Acid Leaching of SRA Phosphor}

A newer phosphor material, $\mathrm{SrAlO}_{2}$ : Eu, Dy (SRA), was also investigated for recovering REEs and the metal content is listed in Table 1 from the previous section. The SRA phosphor is known for its long persistent luminescence and therefore, is commonly used in glowin-the-dark products, such as toys, decorations, or even cosmetic creams. Although the SRA phosphor also has aluminate as the main structure, strontium aluminate could be easier to dissolve in acids than the aforementioned magnesium aluminates since strontium aluminate could be hydrolyzed by water, $\mathrm{SrAl}_{2} \mathrm{O}_{4}+4 \mathrm{H}_{2} \mathrm{O} \rightarrow \mathrm{Sr}^{2+}+2 \mathrm{OH}^{-}+2 \mathrm{Al}(\mathrm{OH})_{3}[32,33]$. As a result, the SRA phosphor could be dissolved completely in nitric acid in less than $1 \mathrm{~h}$ without any peroxide pretreatment. However, applying strong mineral acids is less friendly to the environment. Therefore, organic acids, such as acetic acid and citric acid, were selected as green leaching agents for this research since they are less toxic, easier to handle, and cause less damage to the environment. From our experimental results, shown in Table 4, the REEs in SRA phosphor could be highly dissolved in acetic acid and citric acid for a longer duration (at least $24 \mathrm{~h}$ ). This result is similar to a report by Geroric et al., which used the same organic acids to leach Nd, Pr, and Dy from permanent magnet powder [34]. It is known that these organic acids are relatively weak compared to strong mineral acids. Therefore, the leaching kinetics will be much slower for them to complete the process. Furthermore, we observed that the leaching efficiency of Dy was much higher than that of Eu. A possible reason for this is that Dy has an oxidation state of $3+$, whereas Eu has an oxidation state of $2+$ when being doped in the phosphor. For them to form soluble compounds with acetates and citrates, the REEs would be more preferable in their 3+ oxidation state.

Table 4. Direct acid leaching efficiency (EFF\%) of each metal from SRA phosphor *.

\begin{tabular}{cccccc}
\hline Acid & Time (h) & Dy & Eu & Al & Sr \\
\hline \multirow{2}{*}{ Acetic acid } & 1 & 86.7 & 32.1 & 60.8 & 56.9 \\
$(10 \% v / v)$ & 24 & 90.0 & 71.0 & 88.5 & 80.7 \\
& 48 & 99.9 & 82.7 & 87.5 & 78.3 \\
\hline \multirow{2}{*}{ Citric acid } & 1 & 83.0 & 23.3 & 24.3 & 20.2 \\
$(10 \% w / v)$ & 24 & 88.6 & 62.6 & 73.6 & 67.0 \\
& 48 & 86.6 & 65.2 & 74.3 & 71.3 \\
\hline
\end{tabular}

* Reaction temperature: $50{ }^{\circ} \mathrm{C}$.

Unlike the results from the SFE, there was no selectivity for REEs in the leaching process and it would be unnecessary to calculate the RE\%. An interesting phenomenon was found during the acid leaching of SRA. Since SRA is a long persistent luminescence material, it could glow in the dark for a long period of time. From our experiment, we found out that the glowing of SRA gradually decreased during the course of acid leaching and totally disappeared after the process. Figure 3 shows the luminescence of the SRA phosphor before and after the acetic acid leaching process. The visual result is closely consistent with the quantitative analysis performed by ICP. Therefore, the luminescence intensity could be used to determine the end time of the acid leaching process. 


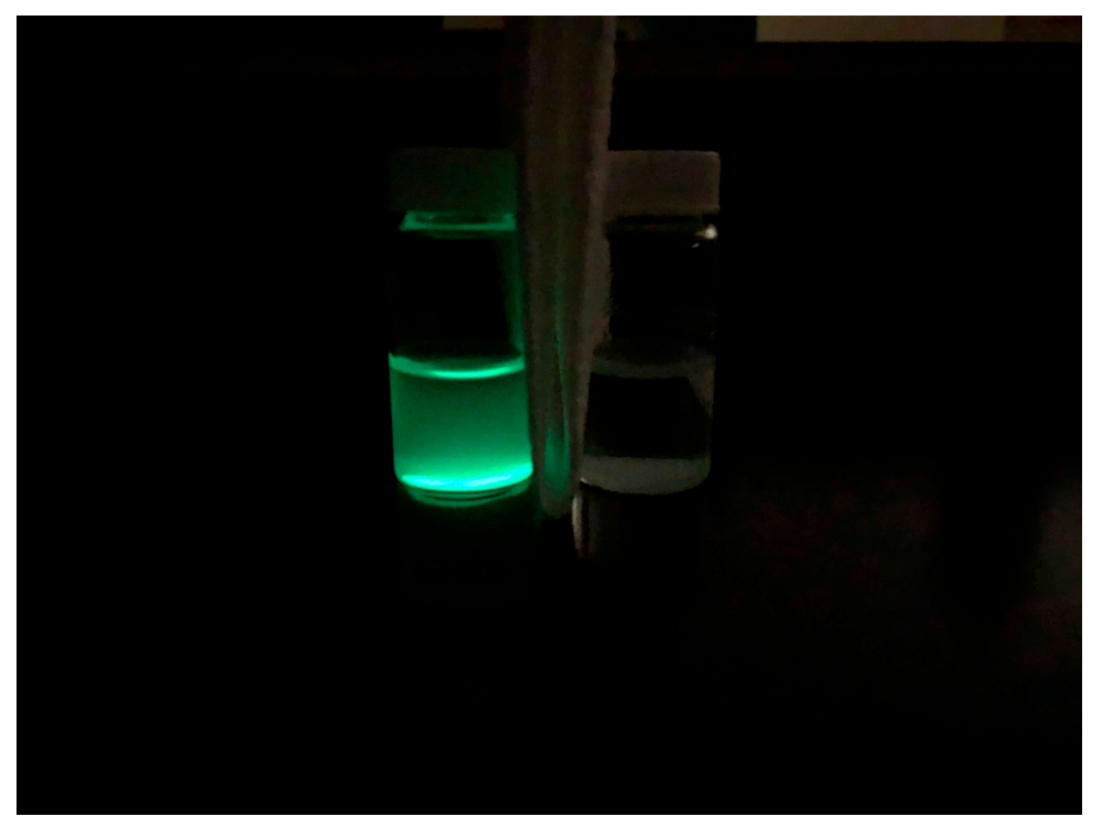

Figure 3. Luminescence of the SRA phosphor before (left) and after (right) acetic acid leaching for $48 \mathrm{~h}$.

\section{Conclusions}

Two processes applying green solvents for recovering REEs from different aluminate phosphor materials have been successfully demonstrated in this report. On the one hand, the extraction of REEs by SFE from peroxide-treated magnesium aluminate phosphor materials resulted in high extraction efficiency (Eu: 92\%) and selectivity (>99\%). The advantage of this process is that it could obtain high purity REEs and, therefore, eliminate the further use of delicate separation technology. On the other hand, direct organic acid leaching of the REEs from strontium aluminate phosphor materials also resulted in a high leaching efficiency (Dy: $>99 \%$ ). The advantage of this process is that it utilizes inexpensive solvents and simple equipment, which could make scaling up easier to achieve. Since different phosphors have their own suitable processing strategies, it is suggested that the waste phosphors should be recycled and collected separately. From our preliminary results of recovering REEs from real waste samples, the SFE technology could maintain high extraction selectivity of the REEs. A more detailed study related to this field will be conducted in the near future as it can provide important information for practical applications. Nevertheless, both green processes appear to be promising for practical recycling of critical REEs from waste aluminate phosphor materials.

Author Contributions: Conceptualization, C.H.Y.; methodology, C.H.Y.; validation, C.H.Y. and R.C.; formal analysis, C.H.Y.; investigation, C.H.Y. and R.C.; data curation, C.H.Y.; writing-original draft preparation, C.H.Y.; writing-review and editing, C.H.Y.; visualization, C.H.Y. and R.C.; supervision, C.H.Y.; project administration, C.H.Y.; funding acquisition, C.H.Y. All authors have read and agreed to the published version of the manuscript.

Funding: This research was funded by the Ministry of Science and Technology, R.O.C. Taiwan (MOST 108-2218-E-126-002) and by Providence University (PU109-11100-A02).

Institutional Review Board Statement: Not applicable.

Informed Consent Statement: Not applicable.

Data Availability Statement: Not applicable.

Acknowledgments: The authors would like to thank C.M. Wai's group members from University of Idaho and R.V. Fox's group members from Idaho National Lab for their support in high pressure experiments. The authors would also like to thank W.Y. Wang's group members from Chaoyang 
University of Technology for their support in rare earth analysis and R.J. Wu's group members from Providence University for their support in the laboratory.

Conflicts of Interest: The authors declare no conflict of interest.

\section{References}

1. Binnemans, K.; Jones, P.T.; Blanpain, B.; Gerven, T.V.; Yang, Y.; Walton, A.; Buchert, M. Recycling of rare earths: A critical review. J. Clean Prod. 2013, 51, 1-22. [CrossRef]

2. Balaram, V. Rare earth elements: A review of applications, occurrence, exploration, analysis, recycling, and environmental impact. Geosci. Front. 2019, 10, 1285-1303. [CrossRef]

3. Jyothi, R.K.; Thenepalli, T.; Ahn, J.W.; Parhi, P.K.; Chung, K.W.; Lee, J.Y. Review of rare earth elements recovery from secondary resources for clean energy technologies: Grand opportunities to create wealth from waste. J. Clean. Prod. 2020, 267, 122048-122073. [CrossRef]

4. Zhang, W.; Noble, A.; Yang, X.; Honaker, R. A Comprehensive Review of Rare Earth Elements Recovery from Coal-Related Materials. Minerals 2020, 10, 451. [CrossRef]

5. Jha, M.K.; Kumari, A.; Panda, R.; Kumar, J.R.; Yoo, K.; Lee, J.Y. Review on hydrometallurgical recovery of rare earth metals. Hydrometallurgy 2016, 165, 2-26. [CrossRef]

6. Ambaye, T.G.; Vaccari, M.; Castro, F.D.; Prasad, S.; Rtimi, S. Emerging technologies for the recovery of rare earth elements (REEs) from the end-of-life electronic wastes: A review on progress, challenges, and perspectives. Environ. Sci. Pollut. Res. 2020, 27, 36052-36074. [CrossRef]

7. Taghipour, H.; Amjad, Z.; Jafarabadi, M.A.; Gholampour, A.; Norouz, P. Determining heavy metals in spent compact fluorescent lamps (CFLs) and their waste management challenges: Some strategies for improving current conditions. Waste Manag. 2014, 34, 1251-1256. [CrossRef] [PubMed]

8. Lee, C.H.; Popuri, S.R.; Peng, T.H.; Fang, S.S.; Lin, K.L.; Fan, K.S.; Chang, T.C. Overview on industrial recycling technologies and management strategies of end-of-life fluorescent lamps in Taiwan and other developed countries. J. Mater. Cycles Waste Manag. 2015, 17, 312-323. [CrossRef]

9. Wu, Y.; Yin, X.; Zhang, Q.; Wang, W.; Mu, X. The recycling of rare earths from waste tricolor phosphors in fluorescent lamps: A review of processes and technologies. Resour. Conserv. Recycl. 2014, 88, 21-31. [CrossRef]

10. Tunsu, C.; Petranikova, M.; Gergoric, M.; Ekberg, C.; Retegan, T. Reclaiming rare earth elements from end-of-life products: A review of the perspectives for urban mining using hydrometallurgical unit operations. Hydrometallurgy 2015, 156, 239-258. [CrossRef]

11. Binnemans, K.; Jones, P.T. Perspectives for the recovery of rare earths from end-of-life fluorescent lamps. J. Rare Earths 2014, 32, 195-200. [CrossRef]

12. Liang, Y.; Liu, Y.; Lin, R.; Guo, D.; Liao, C. Leaching of rare earth elements from waste lamp phosphor mixtures by reduced alkali fusion followed by acid leaching. Hydrometallurgy 2016, 163, 99-103. [CrossRef]

13. Chen, X.; Liu, N.; Mei, G.; Yu, M. Recycling Y and Eu from Waste Fluorescent Powder and High Temperature Solid-State Synthesis of $\mathrm{Y}_{2} \mathrm{O}_{3}$ :Eu Phosphors. Minerals 2017, 7, 44. [CrossRef]

14. Yurramendi, L.; Gijsemans, L.; Forte, F.; Aldana, J.L.; del Rio, C.; Binnemans, K. Enhancing rare-earth recovery from lamp phosphor waste. Hydrometallurgy 2019, 187, 38-44. [CrossRef]

15. Wu, Y.; Wang, B.; Zhang, Q.; Li, R.; Yu, J. A novel process for high efficiency recovery of rare earth metals from waste phosphors using a sodium peroxide system. RSC Adv. 2014, 4, 7927-7932. [CrossRef]

16. Liu, H.; Zhang, S.; Pan, D.; Tian, J.; Yang, M.; Wu, M.; Volinsky, A.A. Rare earth elements recycling from waste phosphor by dual hydrochloric acid dissolution. J. Hazard. Mater. 2014, 272, 96-101. [CrossRef] [PubMed]

17. Zhang, S.G.; Yang, M.; Liu, H.; Pan, D.A.; Tian, J.J. Recovery of waste rare earth fluorescent powders by two steps acid leaching. Rare Met. 2013, 32, 609-615. [CrossRef]

18. Yang, F.; Kubota, F.; Baba, Y.; Kamiya, N.; Goto, M. Selective extraction and recovery of rare earth metals from phosphor powders in waste fluorescent lamps using an ionic liquid system. J. Hazard. Mater. 2013, 254-255, 79-88. [CrossRef] [PubMed]

19. Sinclair, L.K.; Tester, J.W.; Thompson, J.F.H.; Fox, R.V. Supercritical Extraction of Lanthanide Tributyl Phosphate Complexes: Current Status and Future Directions. Ind. Eng. Chem. Res. 2019, 58, 9199-9211. [CrossRef]

20. Shimizu, R.; Sawada, K.; Enokida, Y.; Yamamoto, I. Supercritical fluid extraction of rare earth elements from luminescent material in waste fluorescent lamps. J. Supercrit. Fluids 2005, 33, 235-241. [CrossRef]

21. Liu, Y.; Zhang, S.; Liu, H.; Pan, D.; Liu, B.; Volinsky, A.A.; Chang, C. Free oxoanion theory for BaMgAl $\mathrm{BaO}_{17}: \mathrm{Eu}^{2+}$ structure decomposition during alkaline fusion process. RSC Adv. 2015, 5, 50105-50112. [CrossRef]

22. Liu, H.; Zhang, S.G.; Pan, D.A.; Liu, Y.F.; Liu, B.; Tian, J.J.; Volinsky, A.A. Mechanism of $\mathrm{CeMgAl}_{11} \mathrm{O}_{19}$ : $\mathrm{Tb}^{3+}$ alkaline fusion with sodium hydroxide. Rare Met. 2015, 34, 189-194. [CrossRef]

23. Xie, F.; Zhang, T.A.; Dreisinger, D.; Doyle, F. A critical review on solvent extraction of rare earths from aqueous solutions. Miner. Eng. 2014, 56, 10-28. [CrossRef]

24. Tian, G.; Liao, W.; Wai, C.M.; Rao, L. Extraction of trivalent lanthanides with oxa-diamides in supercritical fluid carbon dioxide. Ind. Eng. Chem. Res. 2008, 47, 2803-2807. [CrossRef] 
25. Liao, C.; Li, Z.; Zeng, Y.; Chen, J.; Zhong, L.; Wang, L. Selective extraction and recovery of rare earth metals from waste fluorescent powder using alkaline roasting-leaching process. J. Rare Earths 2017, 35, 1008-1013. [CrossRef]

26. Wu, Y.; Wang, B.; Zhang, Q.; Li, R.; Sun, C.; Wang, W. Recovery of rare earth elements from waste fluorescent phosphors: Na2O2 molten salt decomposition. J. Mater. Cycles Waste Manag. 2014, 16, 635-641. [CrossRef]

27. Helaly, O.S.; Abd El-Ghany, M.S.; Moustafa, M.I.; Abuzaid, A.H.; Abd El-Monem, N.M.; Ismail, I.M. Extraction of cerium(IV) using tributyl phosphate impregnated resin from nitric acid medium. Trans. Nonferrous Met. Soc. China 2012, 22, 206-214. [CrossRef]

28. Baek, D.L.; Fox, R.V.; Case, M.E.; Sinclair, L.K.; Schmidt, A.B.; McIlwain, P.R.; Mincher, B.J.; Wai, C.M. Extraction of rare earth oxides using supercritical carbon dioxide modified with tri-n-butyl phosphate-nitric acid adducts. Ind. Eng. Chem. Res. 2016, 55, 7154-7163. [CrossRef]

29. Duan, W.; Zhu, L.; Zhu, Y.; Xu, J. Dissolution extraction of uranium oxides and cerium oxide with $\mathrm{TBP}^{-\mathrm{HNO}_{3}}$ complex in supercritical CO2. Procedia Chem. 2012, 7, 184-190. [CrossRef]

30. Tan, Q.; Li, J.; Zeng, X. Rare Earth Elements Recovery from Waste Fluorescent Lamps: A Review. Crit. Rev. Environ. Sci. Technol. 2015, 45, 749-776. [CrossRef]

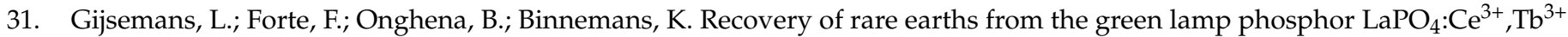
(LAP) by dissolution in concentrated methanesulphonic acid. RSC Adv. 2018, 8, 26349-26355. [CrossRef]

32. Paterson, A.S.; Raja, B.; Garvey, G.; Kolhatkar, A.; Hagstrom, A.E.V.; Kourentzi, K.; Lee, T.R.; Willson, R.C. Persistent Luminescence Strontium Aluminate Nanoparticles as Reporters in Lateral Flow Assays. Anal. Chem. 2014, 86, 9481-9488. [CrossRef] [PubMed]

33. Lu, X. Silica encapsulation study on $\mathrm{SrAl}_{2} \mathrm{O}_{4}: \mathrm{Eu}^{2+}, \mathrm{Dy}^{3+}$ phosphors. Mater. Chem. Phys. 2005, 93, 526-530. [CrossRef]

34. Gergoric, M.; Ravaux, C.; Steenari, B.M.; Espegren, F.; Retegan, T. Leaching and Recovery of Rare-Earth Elements from Neodymium Magnet Waste Using Organic Acids. Metals 2018, 8, 721. [CrossRef] 